\title{
MATERNAL AND INFANT FACTORS ASSOCIATED WITH BREASTFEEDING IN A HOSPITAL ROOMING-IN WARD SYSTEM, KUDUS, CENTRAL JAVA
}

\author{
Indanah \\ Department of Nursing, School of Health Sciences (Stikes) \\ Muhammadiyah, Kudus
}

\begin{abstract}
BACKGROUND: Breast milk is the best nutrition for infants. Breast milk contains a variety of nutrients and fluid that infants need. The practice of breastfeeding may be influenced by several factors, such as maternal knowledge in breastfeeding, maternal competence in lactation management, maternal condition, and infant condition. A new strategy to facilitate breastfeeding is to provide rooming-in one ward system for the new born babies. This study aimed to investigate factors associated with breastfeeding in a rooming-in ward system for the new born babies.

SUBJECT AND METHODS: This study was cross-sectional, conducted in Kudus, Central Java. A sample of 30 lactating mothers was selected from rooming-in ward in a hospital, Kudus, Central Java. The dependent variable was breastfeeding. The independent variables were maternal condition and infant condition. A questionnaire was developed to measure the variables. The data was analyzed using Odds Ratio (OR) and ChiSquare.
\end{abstract}

RESULTS: Good maternal condition $(\mathrm{OR}=15.00 ; 95 \% \mathrm{CI}=1.45$ to $155.30 ; \mathrm{p}=0.008)$ and good infant condition $(\mathrm{OR}=38.25 ; 95 \% \mathrm{CI}=4.59$ to $318.60 ; \mathrm{p}<0.001)$ were positively and strongly associated with the likelihood of breastfeeding.

CONCLUSION: Maternal and infant conditions are important determinants for breastfeeding in a hospital rooming-in ward system.

Keywords: breastfeeding, maternal condition, infant condition, roomingin ward. 